\title{
Application of the high-resolution grazing-emission x-ray fluorescence method for impurities control in semiconductor nanotechnology
}

\author{
J. Szlachetko, ${ }^{1,4, a)}$ D. Banaś, ${ }^{1}$ A. Kubala-Kukuś, ${ }^{1}$ M. Pajek, ${ }^{1}$ W. Cao, ${ }^{2}$ J.-Cl. Dousse, ${ }^{2}$ \\ J. Hoszowska, ${ }^{2}$ Y. Kayser, ${ }^{2}$ M. Szlachetko, ${ }^{2}$ M. Kavčič, ${ }^{3}$ M. Salome, ${ }^{4}$ and J. Susini ${ }^{4}$ \\ ${ }^{1}$ Institute of Physics, Jan Kochanowski University, 25-406 Kielce, Poland \\ ${ }^{2}$ Department of Physics, University of Fribourg, CH-1700 Fribourg, Switzerland \\ ${ }^{3}$ J. Stefan Institute, SI-1001, Ljubljana, Slovenia \\ ${ }^{4}$ European Synchrotron Radiation Facility (ESRF), F-38043 Grenoble, France
}

\begin{abstract}
We report on the application of synchrotron radiation based high-resolution grazing-emission x-ray fluorescence (GEXRF) method to measure low-level impurities on silicon wafers. The presented high-resolution GEXRF technique leads to direct detection limits of about $10^{12}$ atoms $/ \mathrm{cm}^{2}$. The latter can be presumably further improved down to $10^{7}$ atoms $/ \mathrm{cm}^{2}$ by combining the synchrotron radiation-based GEXRF method with the vapor phase decomposition preconcentration technique. The capability of the high-resolution GEXRF method to perform surface-sensitive elemental mappings with a lateral resolution of several tens of micrometers was probed.
\end{abstract}

The production of ultraclean silicon wafers is one of the most important issues for Si-based microelectronics technology. According to the International Technology Roadmap for Semiconductors (ITRS) (Ref. 1), a sensitivity below the level of $10^{9}$ atoms $/ \mathrm{cm}^{2}$ for transition metals on Si wafer surfaces is needed. At present, the total reflection $\mathrm{x}$-ray fluorescence (TXRF) method ${ }^{2-5}$ combined with intense synchrotron radiation (SR) sources offers the best possibilities for measuring very low concentration of impurities on Si surfaces. Using SR beams, a sensitivity level of $10^{8}$ atoms $/ \mathrm{cm}^{2}$ for direct detection of $\mathrm{Cu}$ was achieved. ${ }^{6}$ On the other hand, in the case of low $Z$ impurities, such as $\mathrm{Al}$, the achieved detection limits (DLs) by means of the SR-TXRF technique are still above the ITRS requirements. ${ }^{1,7,8}$ Moreover, the SR-based TXRF technique, which employs the grazing incidence geometry, cannot benefit from the available microfocused x-ray beams at synchrotrons in order to perform high-spatial resolution two-dimensional (2D) surfaces mapping. Therefore, further development of new direct techniques to measure metallic impurities on $\mathrm{Si}$ wafers is still a challenging problem. In this context, the application of the SR based grazing-emission $\mathrm{x}$-ray fluorescence (GEXRF) technique for measuring $\mathrm{x}$-ray emission from $\mathrm{Si}$-wafer impurities can be regarded as a good alternative. In the GEXRF technique, which is a kind of inverse of TXRF, the excited $\mathrm{x}$-ray fluorescence is observed at grazing emission angles $\varphi_{\text {exit }}$ smaller than the critical angle $\varphi_{c} \cdot{ }^{9-12}$ Such a geometry results in a relative enhancement of the characteristic fluorescence emission from the surface with respect to the substantially decreased fluorescence signal from the bulk substrate.

In this paper, we report on a high-resolution GEXRF technique developed for the detection of low-level impurities on Si surfaces. In this method the grazing emission geometry is combined with a wavelength-dispersive spectrometer. The

\footnotetext{
${ }^{a)}$ Electronic mail: szlachet@esrf.fr.
}

measurements were performed at the European Synchrotron Radiation Facility (ESRF) in Grenoble, France, at the beamline ID21, employing a von Hamos-type crystal spectrometer ${ }^{13}$ for the high-resolution detection of the fluorescence $\mathrm{x}$ rays from the impurities deposited on $\mathrm{Si}$ wafers. As for small grazing emission angles $\varphi_{\text {exit }}$, the photon beam spot on the target, observed in the direction defined by the Bragg angle $\theta_{\text {Bragg, }}$, appears as a linelike x-ray source; the spectrometer can be operated in a slit-less mode (see Fig. 1). In such a setup, the angular resolution with which the $\mathrm{x}$ rays were measured at a given exit angle is defined mainly by the crystal Darwin width being of the order of microradians. Due to the slitless operation the detection efficiency of the spectrometer is strongly increased. Moreover, for grazing emission angles tuned below the critical angle for the Si $K \alpha$ line $\left(0.901^{\circ}\right)$, the observed $\mathrm{x}$-ray radiation, which is due to the evanescent waves propagating along the $\mathrm{Si} /$ vacuum interface, gives information only on surface impurities from a depth of a few nanometers. In order to measure the $K-, L-$, and $M$ x-ray fluorescence emission lines of different elements, the von Hamos spectrometer was equipped with ammonium dihydrogen phosphate (ADP) (101), $\mathrm{SiO}_{2}(110)$, and $\mathrm{Ge}$ (220) crystals. With this setup, the spectrometer can

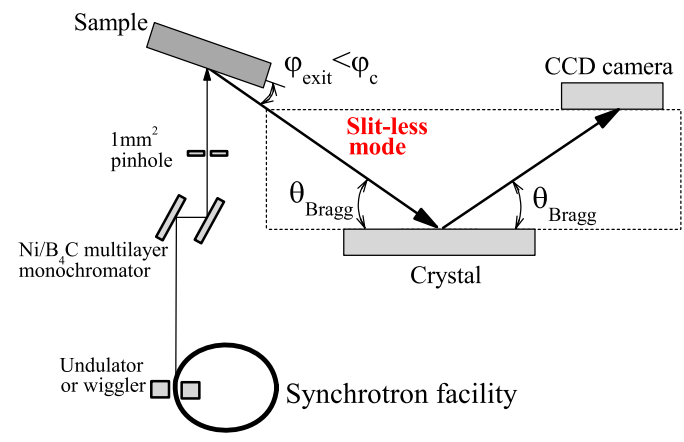

FIG. 1. (Color online) Schematic of the SR based high-resolution GEXRF setup employing the von Hamos spectrometer in a slitless geometry. 


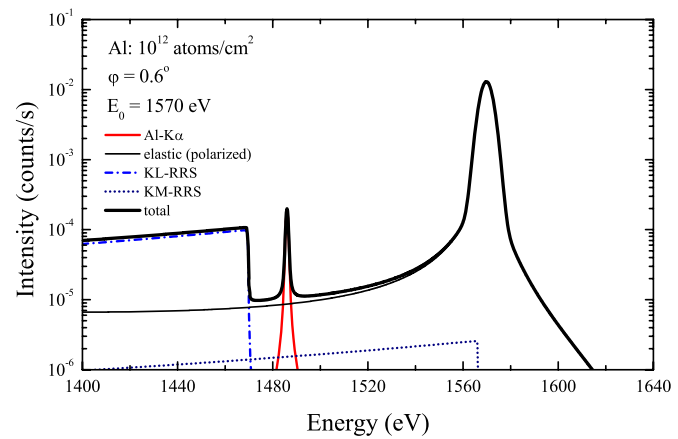

FIG. 2. (Color online) Calculated $\mathrm{x}$-ray spectrum for an $\mathrm{Al}$ contaminated $\left(10^{12}\right.$ atoms $\left./ \mathrm{cm}^{2}\right)$ Si surface showing the Al $K \alpha$ fluorescence line as well as the elastic and Si RRS profiles contributing to the x-ray background.

cover an energy range between 1 and $7 \mathrm{keV}$, in the first order of reflection with an instrumental resolution of about $1-2 \mathrm{eV}$ and an energy bandwidth for a single measurement between 50 and $200 \mathrm{eV}$.

The described high-resolution GEXRF technique was first applied to the study of DLs of Al impurities on silicon. In this case, as reported earlier, ${ }^{6,14,15}$ the DL for $\mathrm{Al}$ is affected by the presence of the $\mathrm{x}$-ray resonant Raman scattering (RRS) process in Si. Indeed, for photon beam energies tuned below the Si $K$-edge in order to avoid the strong $K \alpha$ fluorescence line, the $\mathrm{x}$-ray RRS profile overlaps with the weak fluorescence line from $\mathrm{Al}$ impurities. Consequently, the $\mathrm{x}$-ray RRS background sets a limit for the detection of $\mathrm{Al}$ impurities on Si surfaces. However, guided by theoretical calculations, we found that with the high-resolution technique the x-ray Si RRS profile can be separated from the Al $K \alpha$ fluorescence by an appropriate tuning of the photon beam energy. ${ }^{16}$ The latter should be tuned just above the Al $K$-edge, but not more than the difference between the binding energies of $\mathrm{Si}$ and $\mathrm{Al} 2 p$ electrons, i.e., $27 \mathrm{eV}$, in order to separate the $\mathrm{Al} K \alpha$ fluorescence line from the $\mathrm{Si}$ RRS- $K L$ profile. As an example the calculated spectrum for a photon beam energy tuned $10 \mathrm{eV}$ above the $\mathrm{Al} K$-edge and an instrumental energy resolution of $1 \mathrm{eV}$ is shown in Fig. 2. The $\mathrm{x}$-ray spectra displayed in this figure were calculated for a grazing exit angle of $0.6^{\circ}$, using the expression given by Urbach and de Bokx ${ }^{10}$ and adopting the known cross sections for the RRS, x-ray fluorescence, and elastic scattering of polarized primary photons. In more detail, the x-ray RRS cross sections were calculated using the KramersHeisenberg approach as described in Ref. 16, whereas the Al $K \alpha$ fluorescence and elastically scattering cross sections were calculated by means of the XCOM code. ${ }^{17}$ For the fluorescence emission lines Lorentzian profiles convolved with the instrumental resolution were assumed, while for the primary photons Gaussian profiles were used. It can be seen that in this case only a weak $\mathrm{x}$-ray Si RRS- $K M$ profile resulting from the transition of $3 p$ electrons contributes to the background. Here we would like to point out that in the case of low-resolution (above $100 \mathrm{eV}$ ) detectors the separation of the Al $K \alpha$ line from the Si x-ray RRS profile would not be possible. Following the arguments discussed above, a photon beam energy of $1570 \mathrm{eV}$ was used for the excitation of the $\mathrm{Al} K \alpha$ fluorescence line and the $\mathrm{x}$ rays were observed at a

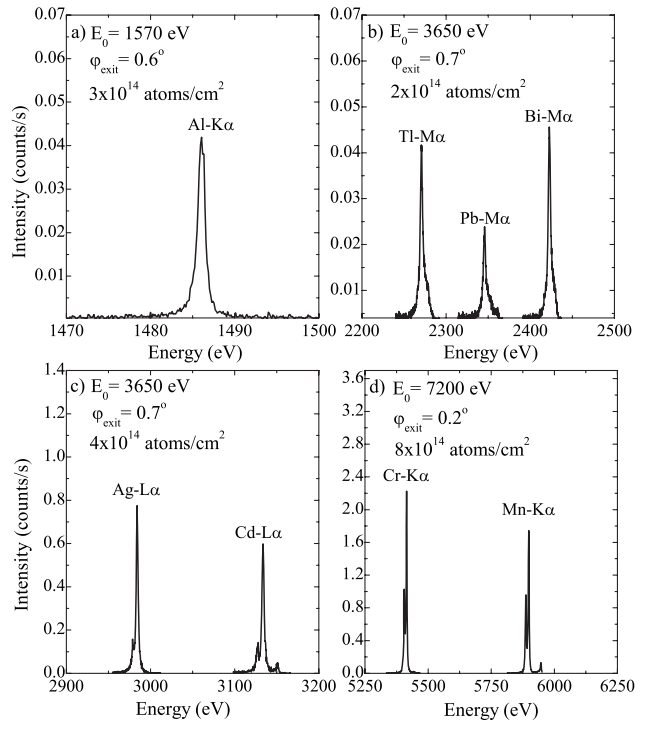

FIG. 3. Examples of the $K \alpha$ (Al, Cr, Mn), $L \alpha$ (Ag, Cd), and $M \alpha(\mathrm{Tl}, \mathrm{Pb}, \mathrm{Bi})$ $\mathrm{X}$-ray fluorescence lines measured by means of the high-resolution GEXRF method for different experimental conditions.

fixed exit angle of $0.6^{\circ}$. which is below the critical angle for the Si $K \alpha$ fluorescence. The x-ray beam delivered by the wiggler was monochromatized by two $\mathrm{Ni} / \mathrm{B}_{4} \mathrm{C}$ multilayers. In such a setup, a beam size of $1 \mathrm{~mm}^{2}$ on the sample with an intensity of about $10^{11}$ photons/s was obtained. To determine the Al DLs, the Si wafers were intentionally contaminated using calibrated $\mathrm{Al}$ solution from Merck.

Further, in order to study more systematically the DLs of the high-resolution GEXRF technique for other elements, the $K \alpha, L \alpha$, and $M \alpha$ fluorescence lines of different elements in the energy range between 2 and $7 \mathrm{keV}$ were measured. For higher excitation energies, the x-ray beam was delivered by an undulator, whereas the same monochromator was used. A photon flux of $10^{12}$ photons/s was obtained. Two photon beam energies were used, namely, $3.65 \mathrm{keV}$ to measure the emission lines of $\mathrm{Y}, \mathrm{Tl}, \mathrm{Pb}, \mathrm{Bi}, \mathrm{Ag}, \mathrm{Cd}, \mathrm{K}$, and $7.2 \mathrm{keV}$ for $\mathrm{Ca}, \mathrm{Ba}, \mathrm{Ti}, \mathrm{Cr}, \mathrm{Mn}$, and $\mathrm{Fe}$. The two series of spectra were measured at emission angles of $0.7^{\circ}$ and $0.2^{\circ}$., respectively, both values being below the critical angle for the $K \alpha$ line of silicon. The samples were prepared using the same procedure as the one described for $\mathrm{Al}$ samples, but in this case, a multielemental (23 elements) standard calibrating solution was used.

As an example, several high-resolution GEXRF $K \alpha, L \alpha$, and $M \alpha$ fluorescence x-ray spectra are shown in Fig. 3. As can be seen, the high-resolution $\mathrm{x}$-ray detection allows for very good separation of the x-ray fluorescence lines. In addition, we found that the measurements performed at grazing exit conditions by means of the high resolution von Hamos spectrometer are characterized by extremely low x-ray background conditions. The measured background in the range of $10^{-4}-10^{-5}$ counts/s corresponds in fact to the noise level of the spectrometer measured without the beam on the sample. Thus, the contribution of the elastically scattered photons, $\mathrm{x}$-ray fluorescence, and $\mathrm{x}$-ray RRS process from the $\mathrm{Si}$ substrate to the measured background is negligible. This result is of prime importance indicating that in contrast with the TXRF method, the high-resolution GEXRF measurements 


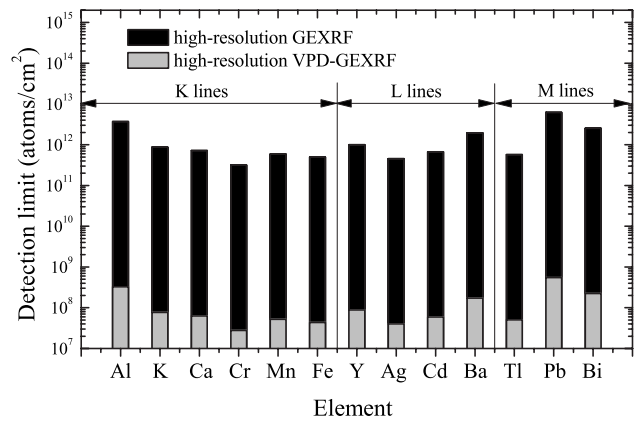

FIG. 4. Determined direct DLs for the present high-resolution GEXRF method (black bars). The estimated DLs for the combined VPD-highresolution GEXRF technique are indicated by gray bars.

can be performed at almost background-free conditions.

The DLs, normalized to a standard measurement time of $1000 \mathrm{~s}$, were obtained from the intensities of the fluorescence line $\left(N_{\text {Peak }}\right)$ and the corresponding background level $\left(N_{\text {Back }}\right)$ by means of the standard expression. ${ }^{2}$ The obtained DLs are depicted in Fig. 4. As shown, the direct DLs of the highresolution GEXRF method are of the order of $10^{12}$ atoms $/ \mathrm{cm}^{2}$. The reported DLs for the TXRF method are similar or better. However, it is no longer the case when the vapor phase decomposition (VPD) preconcentration ${ }^{5}$ technique is used. For the combined TXRF-VPD technique the sensitivity enhancement, for a given wafer size, is indeed determined by the area of the semiconductor x-ray detector window (typically $30 \mathrm{~mm}^{2}$ ), while for the high-resolution GEXRF-VPD the enhancement factor is related to the size of the photon beam spot on the target. In fact, it is given by the squared ratio of the photon beam size on the sample to the wafer diameter. However, this assumption is only valid when the diameter of the dried droplet is smaller than the beam size. As reported earlier, the VPD spot diameter is indeed about a few hundreds of micrometer. ${ }^{18,19}$ Since in our synchrotron radiation based GEXRF technique the beam spot is small, typically $1 \mathrm{~mm}^{2}$, the VPD enhancement factor is up to three orders of magnitude higher than in the TXRF method. Consequently, for wafers about $300 \mathrm{~mm}$ in diameter, lower DLs of the order of $10^{7}$ atoms $/ \mathrm{cm}^{2}$ could be achieved by means of the high-resolution VPD-GEXRF method (gray bars in Fig. 4).

Moreover, the high-resolution GEXRF method combined with microsized SR photon beams provides also a unique possibility for performing surface-sensitive elemental 2D mapping x-ray measurements. In order to probe the mapping capability of this technique one-dimensional (1D) scans across a pattern of $\mathrm{Cr}$ strips deposited on a $\mathrm{Si}$ substrate were performed. The $\mathrm{Cr}$ strips were $10 \mathrm{~nm}$ thick, $80 \mu \mathrm{m}$ wide, and were separated by $80 \mu \mathrm{m}$. The variation in the fluorescence intensities of $\mathrm{Cr} K \alpha$ and $\mathrm{Si} K \alpha$ x-ray lines as a function of the beam position on the sample is shown in Fig. 5. For these measurements, the beam size was $25 \mu \mathrm{m}$ and the striplike $\mathrm{Cr} / \mathrm{Si}$ structure was scanned by moving the sample with a step length of $20 \mu \mathrm{m}$. The fluorescence signal was recorded at emission angles of $0.7^{\circ}$ for $\mathrm{Cr}$ and $2.0^{\circ}$ for $\mathrm{Si}$. As can be seen from the figure, the variation in the $\mathrm{Cr} K \alpha$ fluorescence intensity agrees rather well with the $80 \mu \mathrm{m}$ width of the $\mathrm{Cr}$ layer. For the $\mathrm{Si} K \alpha \mathrm{x}$-ray line the result is similar,

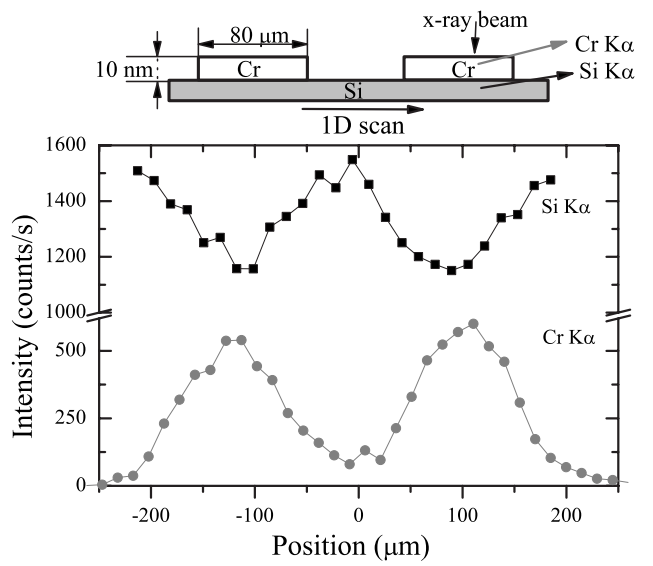

FIG. 5. Results of 1D scans across a pattern of Cr-strips deposited on a $\mathrm{Si}$ sample performed at grazing emission conditions.

but the intensity evolution is reversed. The effect of the absorption of the Si $K \alpha$ x rays in the $10 \mathrm{~nm}$ thick Cr layer is strong due to the small angle of observation. At $2^{\circ}$, the path length of the Si $K \alpha$ x-rays through a $10 \mathrm{~nm}$ thick $\mathrm{Cr}$ layer is about $0.3 \mu \mathrm{m}$ resulting in $\sim 30 \%$ absorption of the Si $K \alpha$ intensity.

This work was supported by the Swiss National Science Foundation (SNSF). One of us (J.S.) acknowledges the financial support from the SNSF (Grant No. PB FR2-118665). The authors would like to thank the ESRF for support and providing our experiment with very good beam conditions.

${ }^{1}$ SEMATECH roadmap, http://public.itrs.net/.

${ }^{2}$ R. Klockenkämper, Total Reflection X-ray Fluorescence Analysis (Wiley, New York, 1997).

${ }^{3}$ S. Pahlke, Spectrochim. Acta, Part A 58B, 2025 (2003).

${ }^{4}$ D. Hellin, S. De Gendt, N. Valckx, P. W. Mertens, and C. Vinckier, Spectrochim. Acta, Part A 61B, 496 (2006).

${ }^{5}$ M. Yamagami, M. Nonoguchi, T. Yamada, T. Shoji, T. Utaka, S. Nomura, K. Taniguchi, H. Wakita, and S. Ikeda, X-Ray Spectrom. 28, 451 (1999).

${ }^{6}$ P. Pianetta, K. Baur, A. Singh, S. Brennan, J. Kerner, D. Werho, and J. Wang, Thin Solid Films 373, 222 (2000).

${ }^{7}$ C. Streli, G. Pepponi, P. Wobrauschek, B. Beckhoff, G. Ulm, S. Pahlke, L. Fabry, Th. Ehmann, B. Kanngießer, W. Malzer, and W. Jark, Spectrochim. Acta, Part A 58B, 2113 (2003).

${ }^{8}$ C. Streli, G. Pepponi, P. Wobrauschek, N. Zöger, P. Pianetta, K. Baur, S. Pahlke, L. Fabry, C. Mantler, B. Kanngießer, and W. Malzer, Spectrochim. Acta, Part A 58B, 2105 (2003).

${ }^{9}$ R. S. Becker, J. A. Golovchenko, and J. R. Patel, Phys. Rev. Lett. 50, 153 (1983).

${ }^{10}$ H. P. Urbach and P. K. de Bokx, Phys. Rev. B 53, 3752 (1996).

${ }^{11}$ P. K. de Bokx, Chr. Kok, A. Bailleul, G. Wiener, and H. P. Urbach, Spectrochim. Acta, Part A 52B, 829 (1997).

${ }^{12}$ G. Wiener, S. J. Kidd, C. A. H. Mutsaers, R. A. M. Wolters, and P. K. de Bokx, Appl. Surf. Sci. 125, 129 (1998).

${ }^{13}$ J. Hoszowska, J.-Cl. Dousse, J. Kern, and Ch. Rhême, Nucl. Instrum. Methods Phys. Res. A 376, 129 (1996).

${ }^{14}$ K. Baur, J. Kerner, S. Brennan, A. Singh, and P. Pianetta, J. Appl. Phys. 88, 4642 (2000).

${ }^{15}$ K. Baur, S. Brennan, B. Burrow, D. Werho, and P. Pianetta, Spectrochim. Acta, Part A 56B, 2049 (2001).

${ }^{16}$ J. Szlachetko, J.-Cl. Dousse, J. Hoszowska, M. Pajek, R. Barrett, M. Berset, K. Fennane, A. Kubala-Kukus, and M. Szlachetko, Phys. Rev. Lett. 97, 073001 (2006).

${ }^{17}$ http:/physics.nist.gov/xcom.

${ }^{18}$ T. C. Miller, C. M. Sparks, G. J. Havrilla, and M. R. Beebe, Spectrochim. Acta, Part A 59B, 1117 (2004).

${ }^{19}$ Y. Mori, K. Uemura, M. Yamagami, and T. Yamada, Spectrochim. Acta, Part A 56B, 2293 (2001). 